International Journal of Environmental Research and

Article

\title{
Extremely Low Frequency Magnetic Field Exposure and Parkinson's Disease-A Systematic Review and Meta-Analysis of the Data
}

\section{Anke Huss ${ }^{1,2, *}$, Tom Koeman ${ }^{1}$, Hans Kromhout ${ }^{1}$ and Roel Vermeulen ${ }^{1,3}$}

1 Institute for Risk Assessment Sciences, Utrecht University, Utrecht 3584CM, The Netherlands; E-Mails: t.koeman@uu.nl (T.K.); h.kromhout@uu.nl (H.K.); r.c.h.vermeulen@uu.nl (R.V.)

2 Institute of Social and Preventive Medicine, University of Bern, Bern 3012, Switzerland

3 Julius Centre for Public Health Sciences and Primary Care, University Medical Centre, Utrecht 3584CG, The Netherlands

* Author to whom correspondence should be addressed; E-Mail: a.huss@uu.nl; Tel.: +31-30-2538461; Fax: +31-30-2539499.

Academic Editor: Martin Röösli

Received: 22 May 2015 / Accepted: 15 June 2015 / Published: 30 June 2015

\begin{abstract}
Objective: To examine the association between occupational exposure to extremely-low-frequency magnetic fields (ELF-MF) and Parkinson's disease. Methods: We systematically searched publications reporting risk estimates of Parkinson's disease in workers exposed to ELF-MF. Summary relative risks were obtained with random effects meta-analysis. Results: We included 11 studies. To assign exposure, four studies evaluated occupational records, four used census, interview or questionnaire information and three used death certificates. Risk of Parkinson's disease was not elevated in workers exposed to ELF-MF with a summary relative risk of $1.05,95 \%$ CI 0.98-1.13. Conclusions: Overall, there was no evidence that the exposure to ELF-MF increases the risk of Parkinson's disease.
\end{abstract}

Keywords: meta-analysis; Parkinson's disease; magnetic field; human 


\section{Introduction}

Since the majority of Parkinson's disease cases are thought to be sporadic, environmental factors may play an important role in the development of the disease [1,2]. One of these environmental factors to be potentially associated with Parkinson's disease is the exposure to extremely-low-frequency magnetic fields (ELF-MF). Since many workers are exposed to ELF-MF above general background levels, this exposure has a potentially strong impact on public health even if the risks to the individual are low. Studies have evaluated both residential [3] as well as occupational [4-12] exposure to ELF-MF. A previous systematic review published in 2006 [13], reviewing papers [4-8], concluded that few studies had shown an association between magnetic field exposure and Parkinson's disease. A recent review did not provide quantitative summaries of the published studies [14]. Since the latest review, several new studies have been published [15-18]. We updated the study base and performed a systematic review and meta-analysis on studies analyzing the effect of occupational ELF-MF on Parkinson's disease.

\section{Methods}

We searched publications in EMBASE and MEDLINE using the search words "neurodegenerative", "parkinson", in combination with "electromagnetic", "electric", "magnetic", "EMF", "electrical", and “occupational”, “occupation", “job”, “work", “workplace”, “worker”, as well as "exposure” or "exposed”. We additionally checked a specialist literature database, using "Parkinson" as search term [19]. We included peer-reviewed papers published in English language until 9 March 2015 if they reported risk estimates of Parkinson's disease in association with ELF-MF exposure. We excluded studies that did not provide estimates of magnetic field exposures.

If risk estimates were presented for more than two ELF-MF exposure levels (e.g., medium exposure versus lowest, and high versus lowest), we pooled risk estimates across all presented exposure categories (except the reference group) to obtain a comparison of "higher versus lowest" exposure, using a within-study meta-analysis. In addition, we extracted risk estimates of the highest (cumulative) reported EMF exposure category ("highest-longest versus lowest"). If both were presented, we preferred adjusted risk estimates over unadjusted ones. If the outcome was assessed from death certificates and presented as primary cause of death or as listed anywhere on the death certificate, we extracted the latter for our analysis. Of a publication on an industrial cohort we used risk estimates reporting on morbidity [6] instead of mortality [20] and of another one the most recent update [17] instead of an earlier publication [12]. Summary risk estimates were obtained with a random effects meta-analysis [21], and an $\mathrm{I}^{2}$ value was calculated, which gives an indication of heterogeneity between the studies [22]. We also checked funnel plot asymmetry using the Egger test [23].

Type of exposure assessment could be related to heterogeneity between study results. In particular, study results could differ depending on whether a complete occupational history was evaluated, or if exposure to ELF-MF was assessed at only one or two points in time (e.g., when using census information). Also, there is consensus that occupations recorded on death certificates are not accurate enough to correctly assign exposure to ELF-MF [24]. We therefore used meta-regression to assess whether type of exposure assessment (job titles from occupational records evaluating the full occupational history, 
from censuses/questionnaires, or the longest held occupation as stated on death certificates) or the type of population (industrial cohort versus general population) was related to heterogeneity between study results. Because Parkinson's disease is not in itself a fatal disease and will therefore only be registered incompletely on death certificates, we additionally evaluated if results of studies differed depending on whether Parkinson's disease was assessed from clinical records or from death certificates.

Given the small number of studies, study characteristics were tested one at a time in separate models. All analyses were performed in Stata version 12 (StataCorp, College Station, TX, USA) with the metan, metareg, metafunnel and metabias commands.

\section{Results}

We screened 177 unique abstracts resulting from our EMBASE and MEDLINE search. We excluded 166 studies for various reasons (81 not about ELF-MF as exposure, 25 not about Parkinson's disease, 18 mechanistic studies, 14 therapeutic studies, 24 reviews, two articles not on occupational exposure and two articles that were updated in later studies) and included 11 studies into our meta-analysis. Study characteristics are given in Table 1.

Job titles were assessed from occupational records [6,9,11,17], from censuses [4,5], from questionnaires evaluating the full occupational history $[15,18]$, or from the longest held occupation as stated on death certificates $[7,8,10]$. Parkinson's disease was either assessed by hospital records [6,15], or death certificates (International Classification of Disease, versions 8 to 10 (ICD-8/9/10), using codes ICD-8 342, ICD-9 332 and ICD-10 G20 (also G21 and G25.9 in Röösli et al. [9]).

Studies reporting on the association between occupational ELF-MF exposures and Parkinson's disease are shown in Figure 1. Heterogeneity between studies was moderate with $46 \%$. Overall, there was no evidence that the exposure to ELF-MF was associated with Parkinson disease, the summary relative risk (sRR) was 1.05 (95\% confidence interval (CI) 0.98-1.13).

Heterogeneity between studies was not explained by the type of exposure assessment (see Figure 1) or whether the study was a general population study or an industrial cohort. There were only two studies $[6,15]$ that used clinical records to identify Parkinson's disease cases rather than mortality but these two studies also provided no evidence for an increased risk of Parkinson's disease in exposed workers; the sRR was 0.81 (95\% C.I. 0.67-1.00). Accounting for the type of outcome assessment slightly reduced heterogeneity between studies $\left(\mathrm{I}^{2}=30 \%\right)$. Nine studies reported risk estimates of highest-longest exposure, which resulted in a sRR of 1.05 (95\% C.I. 0.92-1.20, see Figure 2). Finally, funnel plots were not indicative of funnel plot asymmetry ( $p$-value from Egger test $=0.7$ ). 
Table 1. Characteristics of studies of occupational ELF-MF exposure and Parkinson's disease.

\begin{tabular}{|c|c|c|c|c|c|c|c|}
\hline Study & Design & $\begin{array}{c}\text { Outcome: Source of } \\
\text { Information } \\
\end{array}$ & Population & Exposure & $\begin{array}{c}\text { Exposure } \\
\text { Information Source }\end{array}$ & $\begin{array}{c}\text { Time Point of } \\
\text { Exposure Assessment }\end{array}$ & $\begin{array}{l}\text { Number } \\
\text { of Cases }\end{array}$ \\
\hline Savitz 1998 a [10] & Case-control & Death certificates & $\begin{array}{l}\text { Deceased that had occupational } \\
\text { information on death certificate } \\
\text { from } 25 \text { USA states }\end{array}$ & $\begin{array}{l}\text { Electrical } \\
\text { occupation }\end{array}$ & Death certificates & Primary occupation & 161 \\
\hline Savitz 1998 b [11] & cohort & Death certificates & Electric utility workers & ELF-MF & Occupational records & Occupational history & 117 \\
\hline Johansen $2000[6]^{\mathrm{a}}$ & Cohort & Hospital records & Utility companies & ELF-MF & Occupational records & $\begin{array}{c}\text { Occupation at } \\
\text { baseline/census }\end{array}$ & 68 \\
\hline Noonan $2002[7]^{\text {a }}$ & Case-control & Death certificates & $\begin{array}{l}\text { Deceased aged at least } 60 \text { years } \\
\text { from Colorado, USA. }\end{array}$ & $\begin{array}{l}\text { ELF-MF, } \\
\text { electrical } \\
\text { occupations }\end{array}$ & Death certificates & Primary occupation & 1477 \\
\hline Feychting 2003 [4] $^{\mathrm{a}}$ & Cohort & Death certificates & $\begin{array}{c}\text { Economically active Swedish } \\
\text { population at census }\end{array}$ & ELF-MF & Census & $\begin{array}{c}\text { Occupation at } \\
\text { baseline/census }\end{array}$ & 6101 \\
\hline Hakansson 2003 [5] $^{\mathrm{a}}$ & Cohort & Death certificates & $\begin{array}{c}\text { Industry cohort of engineering } \\
\text { workers }\end{array}$ & ELF-MF & Census & $\begin{array}{l}\text { Occupation at } \\
\text { baseline/census }\end{array}$ & 45 \\
\hline Park $2005[8]^{\mathrm{a}}$ & Case-control & Death certificates & Deceased from 22 USA states & $\begin{array}{l}\text { ELF-MF, } \\
\text { occupation }\end{array}$ & Death certificates & Primary occupation & 33,678 \\
\hline Röösli 2007 [9] & Cohort & Death certificates & Swiss railway employees & ELF-MF & Occupational records & Occupational history & 118 \\
\hline Sorahan 2007 [12] & \multirow{2}{*}{ Cohort } & \multirow{2}{*}{ Death certificates } & \multirow{2}{*}{$\begin{array}{l}\text { Electricity generation and } \\
\text { transmission workers }\end{array}$} & \multirow{2}{*}{ ELF-MF } & \multirow{2}{*}{$\begin{array}{c}\text { Occupational and } \\
\text { location information } \\
\text { with modelled } \\
\text { exposure }\end{array}$} & \multirow{2}{*}{ Occupational history } & 278 \\
\hline Sorahan 2014 [17] & & & & & & & \\
\hline v.d. Mark 2014 [15] & Case-control & Hospital records & General population & $\begin{array}{c}\text { ELF-MF, } \\
\text { electric shocks }\end{array}$ & Interviews & Occupational history & 444 \\
\hline Brouwer 2015 [18] & Cohort & Death certificates & $\begin{array}{c}\text { General population cohort in the } \\
\text { Netherlands }\end{array}$ & ELF-MF & $\begin{array}{l}\text { Questionnaire on } \\
\text { occupational history }\end{array}$ & Occupational history & 609 \\
\hline
\end{tabular}

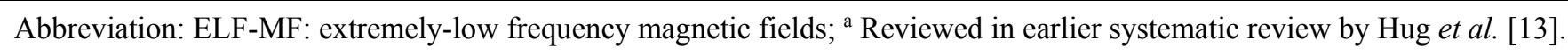




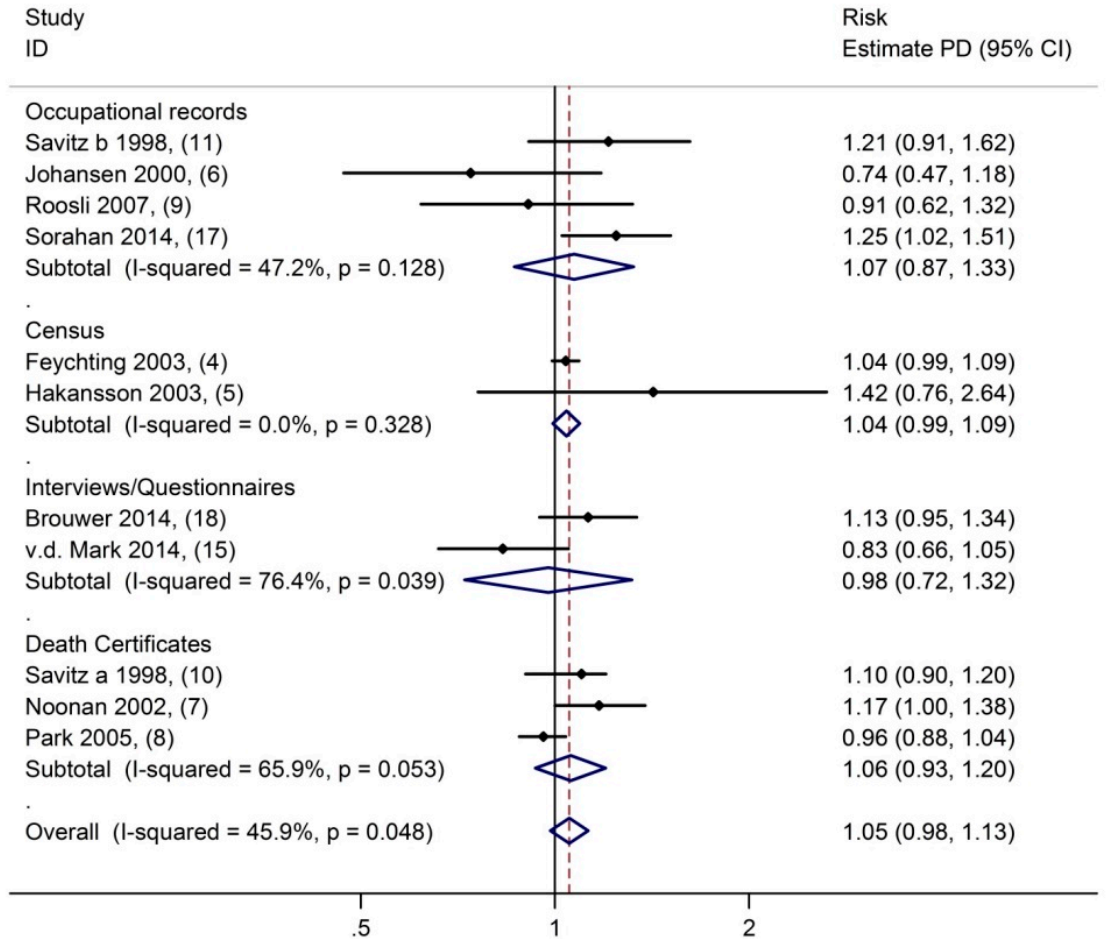

Figure 1. Parkinson's disease in association with occupational exposure to extremely-low-frequency magnetic fields. Comparing higher to lowest exposure to extremely-low-frequency magnetic fields (Numbers in brackets pertain to references).

\begin{tabular}{|c|c|}
\hline $\begin{array}{l}\text { Study } \\
\text { ID }\end{array}$ & $\begin{array}{l}\text { Risk } \\
\text { Estimate PD }(95 \% \mathrm{Cl})\end{array}$ \\
\hline \multicolumn{2}{|l|}{ Occupational records } \\
\hline Savitz b 1998, (11) & $1.80(1.00,3.40)$ \\
\hline Johansen 2000, (6) & $0.64(0.26,1.54)$ \\
\hline Roosli 2007, (9) & $0.91(0.62,1.32)$ \\
\hline Sorahan 2014, (17) & $1.10(0.64,1.87)$ \\
\hline Subtotal $(I-$ squared $=36.9 \%, p=0.191)$ & $1.07(0.75,1.52)$ \\
\hline \multicolumn{2}{|l|}{ Census } \\
\hline Feychting $2003,(4)$ & $1.05(0.92,1.20)$ \\
\hline Hakansson 2003, (5) & $1.11(0.29,4.18)$ \\
\hline Subtotal $(I-$ squared $=0.0 \%, p=0.935)$ & $1.05(0.92,1.20)$ \\
\hline \multicolumn{2}{|l|}{ Interviews/Quest. } \\
\hline Brouwer 2014, (18) & $0.90(0.65,1.24)$ \\
\hline v.d. Mark 2014, (15) & $0.93(0.64,1.34)$ \\
\hline Subtotal $(I-$ squared $=0.0 \%, p=0.896)$ & $0.91(0.72,1.16)$ \\
\hline \multicolumn{2}{|l|}{ Death certificates } \\
\hline Noonan 2002, (7) & $1.50(1.02,2.19)$ \\
\hline Subtotal $(\mathrm{I}$-squared $=. \%, \mathrm{p}=)$. & $1.50(1.02,2.20)$ \\
\hline & \\
\hline Overall (I-squared $=14.8 \%, p=0.310)$ & $1.05(0.92,1.20)$ \\
\hline
\end{tabular}

Figure 2. Parkinson's disease in association with occupational exposure to extemely-low-frequency magnetic fields. Comparing highest-longest to lowest exposure to extremely-low-frequency magnetic fields (Numbers in brackets pertain to references). 


\section{Discussion}

In our meta-analysis we did not identify elevated risks of Parkinson's disease in workers exposed to ELF-MF. Two previous studies that evaluated risks in persons living in close proximity to overhead power lines also found no association with Parkinson's disease $[3,16]$.

Exposure misclassification is of concern in nearly all presented studies, where a variety of methods was used to assign exposure levels to job titles. For example, some studies assigned exposures based on full occupational histories, while others used occupations a person had held at one time point, such as the primary job as reported on death certificates. Within those studies that did not capture the full occupational history, the question arises in how far all relevant ELF-MF occupational exposures during the life course were evaluated. For example, a population-based study in Swedish twins asked for both the longest held job and the last occupation, and found that $31 \%-36 \%$ of the population reported different occupations for primary and last job [25]. A similar percentage of job changes was reported in a Swedish region between the censuses of 1960 and 1970 [26]. However, sRR were not materially different across studies that had applied different methods of exposure assessment. Several studies evaluated exposure response associations. If ELF-MF exposure was associated with Parkinson's disease, then in principle one would expect to observe higher risks among the workers with the highest or longest exposure. This however, was not the case, sRR were equal when analyzed across exposed versus subjects exposed to background-levels or highest exposure category versus subjects exposed to background-levels.

More recently, risk of electric shocks at work has received more attention because it has been hypothesized that such shocks could be associated with the development of Amyotrophic Lateral Sclerosis (ALS) [20]. ALS is a neurodegenerative disease that has been associated with working in so-called "electrical occupations" [27]. Risk of experiencing electric shocks has been reported to be correlated to magnetic field exposures and given that they occur by accident, potential risks arising from electric shocks are more difficult to investigate. Over the last few years, job exposure matrices were developed that identified occupations in which workers are at higher risk of electric shock at work, using registered occupational electrical injuries [28,29]. The two studies that applied one of these electric shock JEMs to their data base, however, did not observe elevated risks of Parkinson's disease in exposed workers $[15,18]$.

By far the majority of studies relied on reporting of the outcome on death certificates, where Parkinson's disease would be expected to be underreported. Underreporting as such would primarily lead to a loss of power in the analysis. Bias would arise if this underreporting was associated with levels of exposure to ELF-MF or if the reported causes of death include false positives. Our study indeed provided evidence that results differed depending on whether the outcome was assessed from death certificates or not. However, assessing Parkinson's disease from clinical records also provided no evidence of increased risks. Finally, funnel plot asymmetry provided no evidence of small study effects. 


\section{Conclusions}

In conclusion, studies so far do not indicate that workers exposed to magnetic fields are at higher risk of Parkinson's disease. This is reassuring given the ubiquity of the exposure in modern life.

\section{Acknowledgments}

Funding: This study was supported by The Netherlands Organization for Health Research (ZonMW) within the program Electromagnetic Fields and Health Research under grant number 85800001, and a grant from the Dutch Health Council.

\section{Author Contributions}

Anke Huss was responsible for the conception and execution, statistical analysis and writing of the manuscript. Tom Koeman was responsible for the data collection, the writing and reviewing of the manuscript. Hans Kromhout gave input in the data analysis and the drafts of the paper. Roel Vermeulen was responsible for the conception of the manuscript and review and critique of the manuscript.

\section{Conflicts of Interest}

The authors declare no conflict of interest.

\section{References}

1. Migliore, L.; Coppedè, F. Genetics, Environmental Factors and the Emerging Role of Epigenetics in Neurodegenerative Diseases. Mutat. Res./Fundam. Mol. Mech. Mutagen. 2009, 667, 82-97.

2. Cannon, J.R.; Greenamyre, J.T. The Role of Environmental Exposures in Neurodegeneration and Neurodegenerative Diseases. Toxicol. Sci. 2011, 124, 225-250.

3. Huss, A.; Spoerri, A.; Egger, M.; Roosli, M.; Swiss National Cohort Study. Residence near Power Lines and Mortality from Neurodegenerative Diseases: Longitudinal Study of the Swiss Population. Am. J. Epidemiol. 2009, 169, 167-175.

4. Feychting, M.; Jonsson, F.; Pedersen, N.L.; Ahlbom, A. Occupational Magnetic Field Exposure and Neurodegenerative Disease. Epidemiology 2003, 14, 413-428.

5. Håkansson, N.; Gustavsson, P.; Johansen, C.; Floderus, B. Neurodegenerative Diseases in Welders and Other Workers Exposed to High Levels of Magnetic Fields. Epidemiology 2003, 14, 420-426.

6. Johansen, C. Exposure to Electromagnetic Fields and Risk of Central Nervous System Disease in Utility Workers. Epidemiology 2000, 11, 539-543.

7. Noonan, C.W.; Reif, J.S.; Yost, M.; Touchstone, J. Occupational Exposure to Magnetic Fields in Case-Referent Studies of Neurodegenerative Diseases. Scand. J. Work Environ. Health 2002, 28 , 42-48. 
8. Park, R.M.; Schulte, P.A.; Bowman, J.D.; Walker, J.T.; Bondy, S.C.; Yost, M.G.; Touchstone, J.A.; Dosemeci, M. Potential Occupational Risks for Neurodegenerative Diseases. Am. J. Ind. Med. 2005, 48, 63-77.

9. Roosli, M.; Lortscher, M.; Egger, M.; Pfluger, D.; Schreier, N.; Lortscher, E.; Locher, P.; Spoerri, A.; Minder, C. Mortality from Neurodegenerative Disease and Exposure to Extremely Low-Frequency Magnetic Fields: 31 Years of Observations on Swiss Railway Employees. Neuroepidemiology 2007, 28, 197-206.

10. Savitz, D.A.; Loomis, D.P.; Tse, C.K. Electrical Occupations and Neurodegenerative Disease: Analysis of U.S. Mortality Data. Arch. Environ. Health 1998, 53, 71-74.

11. Savitz, D.A.; Checkoway, H.; Loomis, D.P. Magnetic Field Exposure and Neurodegenerative Disease Mortality among Electric Utility Workers. Epidemiology 1998, 9, 398-404.

12. Sorahan, T.; Kheifets, L. Mortality from Alzheimer's, Motor Neuron and Parkinson's Disease in Relation to Magnetic Field Exposure: Findings from the Study of UK Electricity Generation and Transmission Workers, 1973-2004. Occup. Environ. Med. 2007, 64, 820-826.

13. Hug, K.; Roosli, M.; Rapp, R. Magnetic Field Exposure and Neurodegenerative DiseasesRecent Epidemiological Studies. Soz. Praventivmedizin 2006, 51, 210-220.

14. Vergara, X.; Kheifets, L.; Greenland, S.; Oksuzyan, S.; Cho, Y.S.; Mezei, G. Occupational Exposure to Extremely Low-Frequency Magnetic Fields and Neurodegenerative Disease: A Meta-Analysis. J. Occup. Environ. Med. 2013, 55, 135-146.

15. Van der Mark, M.; Vermeulen, R.; Nijssen, P.C.; Mulleners, W.M.; Sas, A.M.; van Laar, T.; Kromhout, H.; Huss, A. Extremely Low-Frequency Magnetic Field Exposure, Electrical Shocks and Risk of Parkinson's Disease. Int. Arch. Occup. Environ. Health 2015, 88, 227-234.

16. Frei, P.; Poulsen, A.H.; Mezei, G.; Pedersen, C.; Salem, L.C.; Johansen, C.; Röösli, M.; Schüz, J. Residential Distance to High-Voltage Power Lines and Risk of Neurodegenerative Diseases: A Danish Population-Based Case-Control Study. Am. J. Epidemiol. 2013, 177, 970-978.

17. Sorahan, T.; Mohammed, N. Neurodegenerative Disease and Magnetic Field Exposure in UK Electricity Supply Workers. Occup. Med. 2014, 64, 454-460.

18. Brouwer, M.; Koeman, T.; van den Brandt, P.A.; Kromhout, H.; Schouten, L.J.; Peters, S.; Huss, A.; Vermeulen, R. Occupational Exposures and Parkinson's Disease Mortality in a Prospective Dutch Cohort. Occup. Environ. Med. 2015, 72, 448-455.

19. EMF-Portal, RWTH Aachen University. Available online: http://www.emf-portal.de/ (accessed on 26 June 2015).

20. Johansen, C.; Olsen, J.H. Mortality from Amyotrophic Lateral Sclerosis, Other Chronic Disorders, and Electric Shocks among Utility Workers. Am. J. Epidemiol. 1998, 148, 362-368.

21. DerSimonian, R.; Laird, N. Meta-Analysis in Clinical Trials. Control. Clin. Trials 1986, 7, $177-188$.

22. Higgins, J.P.; Thompson, S.G. Quantifying Heterogeneity in a Meta-Analysis. Stat. Med. 2002, $21,1539-1558$.

23. Egger, M.; Smith, G.D.; Schneider, M.; Minder, C. Bias in Meta-Analysis Detected by a Simple, Graphical Test. BMJ 1997, 315, 629-634. 
24. Andrews, K.W.; Savitz, D.A. Accuracy of Industry and Occupation on Death Certificates of Electric Utility Workers: Implications for Epidemiologic Studies of Magnetic Fields and Cancer. Bioelectromagnetics 1999, 20, 512-518.

25. Feychting, M.; Pedersen, N.L.; Svedberg, P.; Floderus, B.; Gatz, M. Dementia and Occupational Exposure to Magnetic Fields. Scand. J. Work Environ. Health 1998, 24, 46-53.

26. Gunnarsson, L.G.; Lindberg, G.; Soderfeldt, B.; Axelson, O. Amyotrophic Lateral Sclerosis in Sweden in Relation to Occupation. Acta Neurol. Scand. 1991, 83, 394-398.

27. Kheifets, L.; Bowman, J.D.; Checkoway, H.; Feychting, M.; Harrington, J.M.; Kavet, R.; Marsh, G.; Mezei, G.; Renew, D.C.; van Wijngaarden, E. Future Needs of Occupational Epidemiology of Extremely Low Frequency Electric and Magnetic Fields: Review and Recommendations. Occup. Environ. Med. 2009, 66, 72-80.

28. Huss, A.; Vermeulen, R.; Bowman, J.D.; Kheifets, L.; Kromhout, H. Electric Shocks at Work in Europe: Development of a Job Exposure Matrix. Occup. Environ. Med. 2013, 70, 261-267.

29. Vergara X.P.; Kheifets L.; Silva M.; Bracken T.D.; Yost, M. New Electric-Shock Job Exposure Matrix. Am. J. Ind. Med. 2012, 55, 232-240.

(C) 2015 by the authors; licensee MDPI, Basel, Switzerland. This article is an open access article distributed under the terms and conditions of the Creative Commons Attribution license (http://creativecommons.org/licenses/by/4.0/). 